\title{
Factors and Circumstances Leading to Adults Dropping Out from Community Colleges
}

\section{Dr. JP Dhlamini}

Lecturer, Dept. of ABET and Youth Development, College of Education, University of South Africa

\section{Dr. PJH Heeralal}

Senior Lecturer, Department of Science and Technology Education, College of Education, University of South Africa heerapj@unisa.ac.za

\section{Doi:10.5901/jesr.2014.v4n3p449}

\begin{abstract}
This article examines factors and circumstances that lead to learner dropping out. It also investigates the extent of relevancy of what the adult centre is providing towards meeting the needs of adult learners. Theory of transmission learning by Freire which establishes that adult learners are thinking subjects as are the teachers. Qualitative research design was used to collect data. A total of eighteen respondents participated in the research. Semi-structured interviews were conducted with five facilitators and thirteen adult learners. Education that adults receive has to be relevant in the sense that it helps them to fight against illiteracy, poverty and unemployment. In line with literature, findings demonstrate that inadequate resources and facilities, irrelevant curriculum that does not meet the entrepreneurial needs and different skills for the learners are contributing towards dropping of learners. The study therefore recommends that a wider and diversity curriculum be made available to cater different needs of learners and arouse their interest in learning if the feel that learning is relevant to them.
\end{abstract}

Keywords: adult learners, drop-outs, curriculum needs, learning outcomes, self-directed learning.

\section{Introduction and Background}

Adult education forms the essential part of all strategies for development (Nafukho, Amutabi and Otunga 2005). It also includes obtaining knowledge about the environment, human rights, demography and social development, the status of women, human settlement, and food security. The acquisition of knowledge, skills and attitudes assist the adult population to transform their circumstances and gain greater control over their lives. Gouws, Kruger, \& Burger (2008) refer to this gain as formation of positive self-concept. This will lead to positive self-esteem, self-confidence and they will be able to take charge of themselves and their families. It is thus important for adults to continue learning and not to drop-out of school before achieving the level that will equip them with the skills for self-empowerment (Petri and Govern 2004).

Adult facilitators often do not understand what inspires adult learners to continue learning and engaging in adult education programmes (McKay 2007). This article will underscore that illiterates tend to be motivated by the desire for self-actualisation as any other member of society, and may well stop continuing with classes unless facilitators are more responsive to their needs and aspirations. This view is supported by Knowles learning theory stating that there are six andragogical-pedagogical assumptions: self-concept, experience, readiness to learn, orientation to learning, motivation and the need to know (Knowles 2011).

This article examines in depth the high proportion of relevancy of the curriculum in meeting the various needs of learners. These are some of the contributing factors to the drop out of adult learners in the centre. The primary question for this research is: How relevant is the ABET curriculum/ syllabus to the needs of the adult learners within the community? To satisfactorily answer that question, we also examined the institutional data, period allocation time table used at the centre, and the choice of subjects per level from level one to level four. We also gathered qualitative data from the respondents on the question to the facilitators: Do you experience any drop out of learners before they finish the course? If yes, what do you think are the causes contributing to the dropping of your learners?

One of the prominent leaders, Mr Nelson Mandela, once said, "Education is the only tool to open the doors for the future". Thus in each society education becomes an important tool to close the gap that exist between the adults of today 
who did not have the opportunity to be educated, and the today's generation that enjoys compulsory education. It is also important in that it liberates the mind from the slavery of ignorance.

McKay (2007) supports the above statement, when stating that the lack of compulsory education, and the fact that schools were sites of struggle for liberation, meant that many children did not attend or had disrupted attendance between 1976 and 1994, leaving many without education, thus contributing to the massive need for ABET within the country. According to the Department of Education (1997a) ABET supplies the foundation knowledge, skills, understanding and abilities that are required for improved social and economic life. It also provides understanding that gives people a basis from which they can progress along a chosen career and path in life. However, if adults are not determined to continue learning and on the other hand are not motivated to learn they might not achieve their desired goals.

\section{Literature Review}

Adult learners participate in learning as a result of their own volition, because learning is voluntary, especially with adults. However, they must realise the benefit of their participation or they will drop out from learning. In the transactional process, uniqueness of adult learners is essential if a meaningful educational encounter is realised (Brookfield 2001). Knowles (1998), Merriam and Brocket (1997) refer to adult learning as andragogy which is different from the learning of young children at school. Andragogy is referred to as a theory of adult learning and an art and science of helping adults to learn. It is based on humanistic values of placing the individual at the heart of learning transaction, of believing in the goodness of human nature and potential for growth and fulfilment and valuing autonomy and self-direction. In contrast to andragogy O'Connor (2002) explains pedagogics as the art and science of educating children and is often used as a synonym for teaching.

Paulo Freire advocate theoretical basis of adult learning. He refers to a theory of value and theory of knowledge. As adult learners have different needs, they require knowledge that is worth learning in order to help them achieve their desired goals. For adult learning to be successful, it must meet the needs which incorporate ideas on the needs of the individual, institutions and the society it serves. The following table shows levels of literacy for adults which gives an indication on the importance of ABET in changing the lives of the adults at Ekurhuleni.

\subsection{Adult learners and their various needs}

Adult learners are practical in their approach to learning. They want to know how learning can help them right now. They are not interested in something that may be of value in 10 years-time. Sometimes, through counselling, adults can be persuaded to learn something for the future, but they will learn better when they can expect immediate benefits. As Freire (1998) states that adults derive meaning from everything they learn. This means that adults want to learn something from each course of training for something which will encourage them to continue learning. It is important that adults leave a learning situation with the feeling that they have gained something useful for their life experience.

Knowles et al (1998:105) advocates that the purpose of facilitating adult learning is the notion that it is not sufficient for adult education programmes to satisfy the identified learning needs of the individuals, organisations and society. Rather they should seek to help adult learners transform their very way of thinking about themselves and their world. Brookfield (2001:98) refers to this as perspective transformation. He suggests that this can be achieved through the development of competence in critical reflectivity of the individual adult learner. The most significant personal learning adults undertake cannot be specified in advance in terms of objectives to be obtained or behaviours to be performed. Thus significant personal learning might be defined as that learning in which adults come to reflect on their self-image, change their self-concept, question their previously internalised norms, behavioural and moral, and reinterpret their current and past behaviour from a new perspective. Although, ABET learning programmes are provided at Ekurhuleni, adult learners are not motivated to participate in those programmes so that they could reflect on their self-images and change their self-concepts.

The significant personal learning entails fundamental change in learners and leads them to redefine and reinterpret their personal, social and occupational worlds (Rogers 2009). He further states that the way in which people deal with psychological conflict is to try to flee from the situation causing it, which probably accounts in part for the dropping of learners from adult education. In the process, adults may come to explore effective cognitive and psychomotor domains that they previously had not perceived as relevant to themselves. It is thus imperative for the ABET facilitators to prompt their learners to consider alternative perspectives on their personal, political, work and social 
lives. Hence effective facilitation is the most important aspect of this study to ensure that learners are motivated to participate in learning programmes that are provided at Ekurhuleni.

In addition adult learners become impatient with too much theory or background. They respond best if they are taught simply and directly what they want to learn and what will make a difference to their daily lives. Johnston (2003) characterises liberal adult education as providing individuals with knowledge which they are free to use as they wish, individually or collectively. Liberal adult education sees itself as neutral and embracing learning for its own sake, for citizenship or for other reasons. It is thus important that adult education provides liberal thinking in the minds of the adult learners so that they can be able to change their lives self-image. The most effective facilitator is the one who can encourage adults to consider rationally and carefully perspectives and interpretations of the world that diverge from those that they already hold, without making these adults feel they are being threatened.

\subsection{Enrolment of adults at adult education centres}

This article focuses on the reflections of drop-out of adult learners from the adult learning centres. Knowles, Holton, \& Swanson (2005) indicate that it is important to prepare learners for the new knowledge they will receive. They also need to be motivated to participate in learning by making the content meaningful and connected to the learner's needs. Paulo Freire emphasises that human learns through his/her own transforming action in the world. It is the learner who constructs his own categories of thought, organises his life and transforms the world. It is thus important for the facilitator to understand the world of the learner, which will enable him to have better understanding and know what learners will like.

The following table reflects the statistics of the enrolment as well as dropout rate in 2010 of ABET learners. The table shows the performance of AET which as mentioned above as this is important in advancing the lives of adults. This table reflects the key issues and challenges faced by facilitators on how to motivate adult learners so that they don't drop out but continue with adult learning programmes.

Adult Education Enrolment in South Africa

\begin{tabular}{|l|c|c|c|c|c|c|c|}
\hline \multicolumn{7}{|c|}{ AE Enrolment statistics in 2010 } \\
\hline Province & Males & \multicolumn{2}{c|}{ Females } & \multicolumn{3}{c|}{ Totals } \\
\hline & Entries & Wrote & Entries & Wrote & Entries & Wrote & $\%$ Wrote \\
\hline Western Cape & 1194 & 980 & 1181 & 8951 & 2375 & 1875 & 78.95 \\
\hline Limpopo & 3338 & 2419 & 20162 & 14607 & 23500 & 17026 & 72.45 \\
\hline Eastern Cape & 2257 & 1611 & 9437 & 6829 & 11694 & 8440 & 72.17 \\
\hline Gauteng & 4405 & 3047 & 6838 & 4737 & 11243 & 7784 & 69.23 \\
\hline KwaZulu Natal & 3255 & 2065 & 14458 & 9781 & 17713 & 11846 & 66.86 \\
\hline Northern Cape & 522 & 322 & 1524 & 1029 & 2046 & 1352 & 66.03 \\
\hline North West & 2119 & 1288 & 5499 & 3474 & 7618 & 4762 & 62.51 \\
\hline Free State & 1420 & 821 & 3531 & 2221 & 4951 & 3042 & 61.44 \\
\hline Mpumalanga & 2816 & 1360 & 12360 & 6377 & 15166 & 7737 & 51.02 \\
\hline National & $\mathbf{2 1 3 2 6}$ & 13913 & $\mathbf{7 4 9 8 0}$ & $\mathbf{4 9 9 5 0}$ & 96306 & $\mathbf{6 3 8 6 3}$ & $\mathbf{6 6 . 3 1}$ \\
\hline
\end{tabular}

The above statistics are from the Department of Education (2011) and show the enrolment of adult learners who are registered at $A B E T$ centres in various provinces in South Africa. The national statistics show that in 2010 from all nine provinces of South Africa, there was a total of 21326 males and 74980 female adult learners who registered. That gives a total of 96306 learners. Out of that number there were 13913 males and 49950 females who were able to write final assessment at the end of the year. Contrary to the registrations, 7413 males and 25030 females, that is a total of 32443 learners dropped on learning programmes in 2010. The focus of this article is on adult learners in Gauteng Province. Where there were 11243 adult learners enrolled at various adult centres. But 7784 adult learners wrote which is $69.23 \%$. Therefore, 3459 adult learners did not write, or dropped, such numbers are converted to percentages on the bar graph below. 


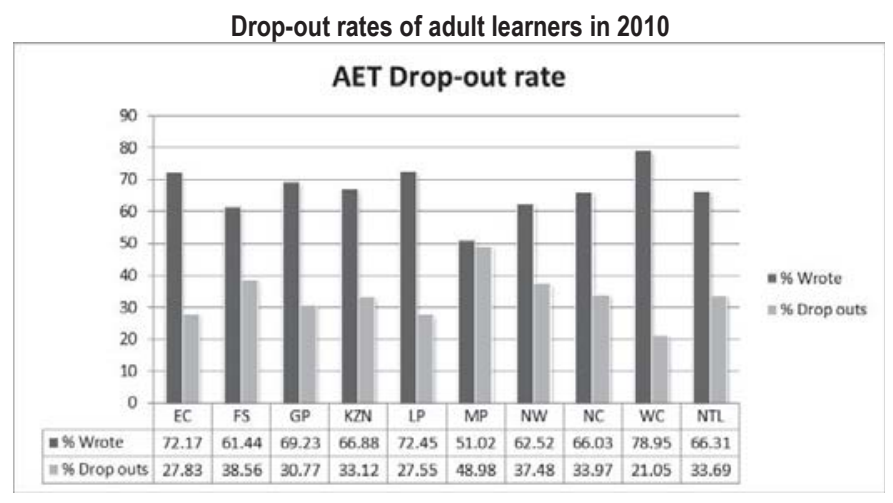

These statistics are from the Department of Education (2012). The graph shows enrolment and drop-out rates in adult learning centres. This article focuses on the critical reflections of the causes of drop-out of adult learners in the learning centres and how they could be motivated so that they do not drop out at the rate reflected on the above statistics. The implementation of more effective methods might bring results in positive willingness on the part of the learners. The total number of learners who enrolled at ABET centres in Gauteng in 2010 was 11243 learners. $69.23 \%$ learners were able to write their final assessment and $30.77 \%$ dropped out before the completion of the course. One could be wondering as to what is the major reason of drop-out of adult learners.

\subsection{The Drop-out rates in the adult centre}

Facilitators stated that at the beginning of the year a large number of adult learners come to register at the centre. Facilitator 4 said that it was due to the effective methods of recruitment used by the centre. She continued saying that sometimes they had their classes full at the beginning of the year. Learners register with the enthusiasm to learn. But as time progresses, the attendance decreases.

The following table reflects the actual enrolment statistics at the beginning of the year and the drop-out rates before learners wrote their final assessment at the adult centre (Department of Education 2010:3).

Table reflecting drop-out rate of learners numerical

\begin{tabular}{|l|c|c|c|c|c|}
\hline Year & $\mathbf{2 0 1 1}$ & $\mathbf{2 0 1 0}$ & $\mathbf{2 0 0 9}$ & $\mathbf{2 0 0 8}$ & $\mathbf{2 0 0 7}$ \\
\hline No Enrolled & 992 & 803 & 900 & 806 & 786 \\
\hline No Wrote & 609 & 595 & 504 & 549 & 543 \\
\hline No Dropped out & 383 & 211 & 395 & 257 & 243 \\
\hline
\end{tabular}

The above table shows the enrolment of learners for the past five years and those who finish on the course and the number of drop-outs rates of learners who did not finish the course. In 2011, 992 learners registered at the beginning of the year, 609 learners wrote the end of the year examination and 383 dropped out before the end of the year. There were 803 learners who registered at the beginning of the year 2010, 595 learners wrote the final examinations and 211 learners dropped out before finishing the course. In 2009 there were 900 learners who registered at the beginning of the year, 504 learners wrote end year examinations, and 395 learners dropped out. 806 learners registered in 2008, 549 wrote their final examinations, while 257 learners could not write their exams. Lastly, there were 786 learners who registered in 2007, with 543 learners who wrote their final assessment, and 243 learners who did not write examinations as they dropped out.

This was the indication that there is a problem with the dropping of adult learners. There might be various reasons towards the prevailing situation that need an urgent attention to prevent the continuous occurrence in adult education.

The following bar graph indicates the drop-outs reflected in percentages of the learners at the ABET centre for the past five years rates. This shows a relatively high percentage of learners who do not write their final assessment, for various reasons mentioned as by the respondents. 


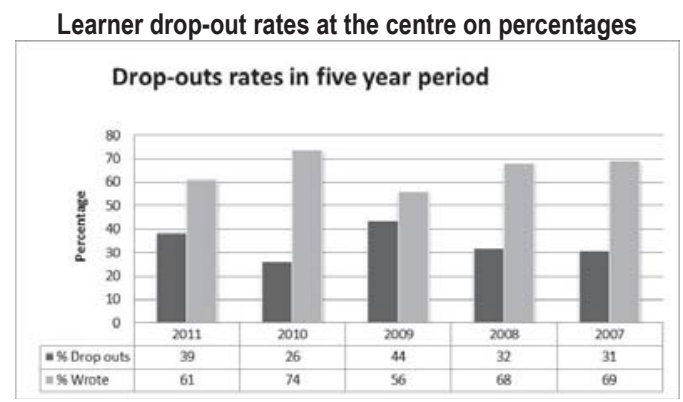

The above table shows the drop-out rate in percentages for the past five years reflecting the percentages of learners at the beginning of each year. It further shows the number of learners who wrote the final assessment at the end of the year. Then it also reflects the drop-out rates of learners who did not write final assessment and some of them dropped early in the year for various reasons. These percentages show learners in the adult centre at Ekurhuleni which reflects correlation in it and the drop-out rates of the whole country as shown above. The pie-chat below shows the scope of literacy in South Africa in relation to the drop-out rates of learners in 2010. The National drop-out was at $33.69 \%$ of adult learners who did not write final examinations. It also reflected that $66.31 \%$ adults wrote their final assessment in 2010.

This table above reflects that in 2011 there were 992 adult learners who enrolled, but $61 \%$ wrote final assessment, and $39 \%$ dropped-out. In 2010,803 adult learners registered at the beginning of the year, $74 \%$ were able to write the final assessment and $26 \%$ dropped out. In 2009, 900 learners registered at the beginning of the year, 56\% wrote final assessment and 44\% dropped-out. In 2008, 806 learners registered, 68\% wrote their final assessment and 32\% dropped-out. Lastly in the year 2007, 786 learners came for registration, $69 \%$ wrote their final assessment at the end of the year, 31\% dropped-out (DoE 2012).

McKay (2007) says that the illiterate group has increased in spite of policy changes and the introduction of compulsory education. This latter-mentioned group, as well as those who have not had any schooling, also reflects the number of South Africans who fall within the scope of ABET. Moreover, South Africa still has large numbers of out of school youth, which will maintain the long-term need for $A B E$.

The following pie chart shows only $1 \%$ of adults are presently participating in learning programmes. These learners will continue with learning and will probably never drop-out, as reflected and discussed in detail above. The enrolment of learners in the centre for adult education in Gauteng province is $69.23 \%$. Before they write their final assessment, $30.77 \%$ of these learners drop out. Taking into consideration that they constitute only $1 \%$ of black adults, it becomes very important to find out how these learners can be better motivated and at the same time, attract those who are not yet involved in learning.

The scope of literacy in South Africa

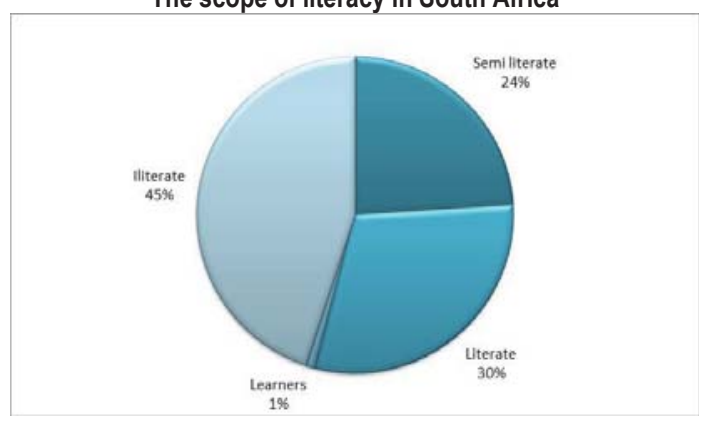

The above pie chart shows that illiteracy rates in South Africa are high and stand at about $45 \%$ of the population of over 15 years of age, which shows adults who never went to school. A further $24 \%$ are semi-literate. There are $30 \%$ of literate adults according to the pie chart. The reflection also shows that only $1 \%$ of adults are presently involved in learning. There is general consensus that internationally the drop-out problem has reached the epidemic proportions. However, this has also become a problem globally that is facing education fraternity (Patrick 2008 and Wotherspoon 2004). The 
above drop out figures in South Africa reflects this as a problem that affects each province and eventually affecting the entire community.

There could be a number of factors that result to this situation. Machingambi (2003) states that the lack of diversity in the curriculum provided at the centres can predispose learners into dropping out. Freire (1998) contends that adults should acquire the skills necessary to achieve the potential of their personalities. Every person has capacities that if realised, will contribute to the wellbeing of himself/herself and of the society. On the other hand Wotherspoon (2004) underlines the influence of other factors central to dropping out problems, such as, policies and practices; the nature of curriculum; available resources and quality of learning.

\subsection{Statement of the Problem}

Dropping out of adult learners still remains one of the major problems facing the ABET centres. Learners register at the beginning of the year, but as they continue in the year, they eventually drop out before completion. The main purpose of this article was to investigate and examine the factors and the circumstances that lead to the dropping of adult learners.

\section{Methodology}

\subsection{Research design}

Research design for this article is advised by the nature of information needed by the researchers. White (2005) supports this idea in that the researcher's actions and choices determine the design. We needed to collected concrete data from the documents used at the centre, for example the time table and curriculum documents. The in-depth understanding of the students and facilitators' view on the causes of drop out of learners from the centre was imperative.

\subsection{Population and sample}

Population at the centre is $01(\mathrm{~N}=01)$ principal, $09(\mathrm{~N}=09)$ HODs or supervisors, $42(\mathrm{~N}=42)$ facilitators. The total numbers of teaching staff is $52(\mathrm{~N}=52)$ and $992(\mathrm{~N}=992)$ learners. From this population a sample of was selected. Two focus groups of thirteen learners and five facilitators were conducted.

\begin{tabular}{|c|c|}
\hline \multicolumn{2}{|r|}{ Biographical data of sampled facilitators } \\
\hline Variable & Adult Centre \\
\hline Gender & $\begin{array}{l}02=\text { males } \\
03=\text { females }\end{array}$ \\
\hline Qualification & $\begin{array}{l}03=\mathrm{ABET} \text { Diploma } \\
02=\mathrm{ABET} \text { Diploma and ACE certificate }\end{array}$ \\
\hline Experience & $\begin{array}{l}01=\text { More than } 3 \text { years } \\
04=04-25 \text { years }\end{array}$ \\
\hline Positions & $02=$ Heads of the Department, Supervisors and Facilitators \\
\hline Date of the interview & 06 September 2012 \\
\hline
\end{tabular}

The above information reflects the presentation of the facilitators at the sampled centre. It shows the biographical data of the supervisors or managers together with the facilitators who participated in the interviews. There were in all 2 males and 3 females. This information contains the gender of the participants. The qualifications of the facilitators show that 3 have an ABET Diploma and 2 have an ABET Diploma and the Advanced Certificate in Education (ACE). The work experience of the facilitators in ABET shows that 1 facilitator has 1 to 3 year experience in teaching and 4 facilitators have between 4 and 25 years working experience.

The sampled facilitators (teachers) held different positions at the centre: 2 facilitators were in a management position, and 3 were facilitators. It was interesting to discover that two facilitators are furthering their studies in the field of adult education. Two are studying towards Bachelor of Education (Bed) Degree in ABET.

It was also important to present the biographical data of the learners in the adult learning centre who participated in the interviews. 
Biographical data of sampled learners

\begin{tabular}{|l|l|}
\hline Variable & Adult centre \\
\hline Gender & $05=$ males \\
& $08=$ females \\
\hline \multirow{3}{*}{ Age } & $18-25=03$ \\
& $26-40=04$ \\
& $41-$ above $=06$ \\
\hline \multirow{3}{*}{ Levels } & L $2=03$ \\
& L $3=05$ \\
L $4=05$ \\
\hline Date & 11 September 2012 \\
\hline
\end{tabular}

The above biographical data was for a focus group of learners who participated in the interviews. The group was formed of both males and females. There were 5 males and 8 females respondents. It was important for the purpose of this study to get the views of both genders on what are the factors and circumstances that yield to learners dropping out at Ekurhuleni adult centre. It was essential to the study to get respondents of a variety of groups in order to collect data reflecting different views. There were 3 learners between the ages of 18-25, 4 learners between 26-40 years and 6 learners from age of 41 and above. This information shows the combination of different academic levels of learners sampled to participate. There were 3 level 2 learners, 5 level 3 learners and 5 level 4 learners, which gave a total of 13 respondents. This was done in order to interact with learners from different levels of competency, and to gain different perceptions from them.

\subsection{Interviews procedure}

Two focus groups interviews were conducted through the use of an interview schedule in order to guide researchers on the relevant questions (De Vos 2011). Interviews were conducted at the adult centre at Ekurhuleni with an aim of investigating the factors and the circumstances leading to the dropping of learners in the centre.

Fundamental questions to the facilitators and learners were:

1. Do you experience any drop out of learners before they finish the course? If yes, what do you think are the causes of dropping of learners? From this major question probing questions followed.

To the learners different questions were asked:

2. How relevant is the ABET curriculum/ syllabus to your needs as learners?

3. For how long have you been attending ABET classes and do you find them interesting?

During the informal conversational interview, questions emerging from the immediate context were asked in the natural course of setting and responses were made. These questions were asked to gather data on the relationship between the existing curriculum at the centre, the subjects that are taught and the individual needs of learners.

\section{Results and Discussions}

The reasons for drop-outs as stated by the respondents were as follows

There are various reasons that were put forward as the major causes for the drop-out of learners in the adult centre.

- Relevance and time allocation to the subjects

- Nature of curriculum and lack of interest in subjects offered

- Unavailability of the resources and physical environment

\subsection{Relevance and time allocation to the subjects offered at the centre}

The major question was asked to the facilitators to indicate the causes of dropping of learners before they finish the course. Learners are complaining about the time allocation for each subject. Some of the subjects that are taught were not interesting to them. Facilitators stated that at the beginning of the year a large number of adult learners come to register at the centre. Facilitator 3 said that it was due to the effective methods of recruitment used by the centre. She continued saying that sometimes they had their classes full at the beginning of the year. Learners register with the enthusiasm to learn. But as time progresses, the attendance decreases. 
Learning at the adult centre starts in the afternoon at $14 \mathrm{H} 30$ and lasts until 18H30. Level 2 learners attend for 2hours per day, four times per week. They attend numeracy on Tuesday only. When they come the following week on Tuesday for numeracy lesson again, they would have forgotten what they learnt the previous week. The time table showed that language is learnt only once a week. Even English as First Additional language is done only once a week. Learners do not get enough time to practice the language.

Learner 4 said that the adult centre starts in the afternoon because there is no accommodation for them in the morning as the school is being used by the primary school. During the day they are not engaged in anything because most of them are unemployed. They would like to start with the school in the morning. Learner 4 said that the afternoon is not suitable for them because they must cook for their families', look after their children when they come back from school, because there was a lot of crime in the area, at the same time they must be in class. Learner 2 said:

\begin{abstract}
"We attend only one subject per day, per week. When the following week comes you find that we have forgotten all what we learnt the previous week. We learn IsiZulu on Monday, numeracy on Tuesday, integrated studies on Wednesday and English on Thursday. We only attend for two hours a day. This is our biggest problem because we forget as we are adults".
\end{abstract}

As reflected in the above class attendance time table there was very little time allocated for each period. The facilitators were asked about the relevance of the learning areas that are offered at the centre, to the needs of the learners. Facilitator 2 responded by saying that the integrated subject was confusing to the learners. It contained clustered information. Most learners find it difficult to understand. Another problem is that all these integrated subjects do not have the necessary resource material, like the other learning areas.

It seemed as if the interests and the needs of the learners were not catered for. This was stressed by learner 5 when she said:

"We would like to learn basic reading and writing skills and also be equipped with skills that empower us to start our own businesses. As the unemployment rate is high in our country and some of us are living in poverty, adult education should help us to get a better life. The centre should try to provide us with skills for gardening, sewing, baking, and many more so that we can form a co-op. These co-ops will help us to alleviate poverty".

\title{
4.2 Nature of the curriculum and its influence on dropping out
}

It was discovered that the curriculum design provided at the centre concentrated more on philosophical contents of the curriculum and therefore tends to neglect the more practical aspect of the curriculum, which is of greater relevance to the adult learner. There was a concern that most ABET materials and teaching focused on the basic education and literacy components of $\mathrm{ABET}$ and have not incorporated the skills training and development aspect which should be aligned with an ABET programme. McKay et al (2007) contend that adult education should assist adult learners to develop knowledge and skills they would need for their own personal development.

Findings from this study are also consistent of Okech (2004) who found out that in Ghana some of the curriculum related factors that contribute towards drop outs are that the curriculum is not in harmony with the needs of the learners. Learners feel bored and not satisfied with the prescribed curriculum that does not fulfil their needs and expectations of the community. This idea is also supported by Paulo Freire (1998) stating that adults should acquire the skills necessary to achieve the potential of their personality. Although ABET curricular may currently be viewed in a negative light, the need exists for curricula to be redesigned so that they meet learners' needs and standards, rather than the standards set by the institution.

Respondents stated that curriculum at the centre is irrelevant to their world of work. Some of the learners were working, so they saw the curriculum not meeting their work related needs. Such learners needed to focus on communication skills and other skills that are direct to their job related competency. For those respondents who were not working stated that they need curriculum that will help them to address economic and social problems. Adults should understand their society and should be skilful in directing social change (Friere 1998).

Facilitator 1 stated that the development of primers was the responsibility of the Department of Basic Education. This is based on what the subject facilitators and curriculum developers from the Head office and the District office of the Department on Basic Education estimate as the best curriculum for adult learners.

There was no consideration of the learners needs. As these were adult learners, they possess prior knowledge, thus Recognition of Prior Learning (RPL) should be considered. Adult learners already possess knowledge and experience which require refinement which might be done through acquisition of ABET skills. This is justified by the fact 
that all level 2, 3 and 4 learners receive workbooks at the adult centre from the Department of Basic Education. The workbooks are designed according to level of understanding for that specific level. However, facilitators are not conversant with the curriculum and the ways and the approach to be used for the subjects.

When facilitators were asked about the developmental workshops conducted to prepare them to implement the new curriculum that would be understood by the learners, and be able to use the workbooks. Facilitator 2 stated that sometimes they receive two-hour training workshops. However, those workshops were not necessarily based on the understanding of the curriculum, but on new developments within the Department of Basic Education (DoE 1997b)

Respondents revealed that the subject content was confusing to them. It does not help them to achieve their intended goals. Learner 7 said,

\begin{abstract}
"I have been with this adult centre for two years now, but still I cannot read and write. I do come to school, although not always due to some commitments. I also want to know how to speak English, but I don't know it. I am trying my best to learn and do as I am told but I cannot read even my mother language. I think I do have a problem which must be solved by my teachers".
\end{abstract}

The selection and the provision of the subject content rely on the packages that were allocated for each level. Time table that was drawn up at the centre controlled the time allocated for each subject. It has proved that the time allocated is not enough for the learners to learn effectively. The time-table that is used at the centre was as follows:

\title{
4.3 Unavailability of the learning resources and physical environment
}

Respondents stated that at the beginning of the year they come in large numbers, but as time progresses they lose interest in going to school. When they were asked for the reasons, they said that they did not have enough time to attend classes. They gave the reason that if they do not get the skills that they were thinking they would get at school. When they were asked the reason for doing that, they said learners become so attached to their facilitators in such a way that they don't want to proceed to the next level.

During observation, data revealed that the classroom environment was not welcoming and motivating for adult learners. The classroom furniture, the chairs and tables were too low for the adults to use. Learners were complaining that they are so tiring and it causing difficulty to stand up. The educators do not have space to store their teaching material, such as books, chalk, duster, extra learning material. They must carry along all those items to home and to school the next day. There were no cupboards available for them to store their teaching material. Learners do not even have learning and teaching support material (LTSM) to enhance learning. Learners rely on workbooks only which are distributed at the beginning of the year. The whole classroom environment was not conducive for learning.

Research studies conducted in Uganda have shown that physical environmental factors are prove to be a contributing factor towards learner drop-out from the learning programme. The lack of physical facilities and equipment that teachers will use in the classroom like the charts, learner resources contribute towards drop-out rate of learners. This article also revealed that poor conditions of resources are also a contributory factor. Education facilities are linked to quality in terms of human resources and in learning centre resources. Availability of resources such as textbooks, desks, chalkboards has found to influence dropouts (Okech 2004).

\section{Conclusion}

Most learners do not attend on regular bases. Facilitators do not have any space available to store their LTSM, and learners do not have the learning material. The fact that the curriculum does not meet the needs of the learners so they see themselves not benefiting and contributing to the economy of the country hence they drop-out. They are not learning any skills that will equip them to obtain their goals and alleviate poverty. Recognition of Prior Learning is not considered at all, although learners would have liked that their previous experiences be recognised and be used as a stepping stone towards their learning. This study has also revealed that all such factors should be considered in order to help adults not to drop out.

\section{Recommendations}

Recommendations to this study are made on the basis of the findings and discussions conducted. The following has been made to assist adult learners stay at the centre: 
- The centre should widen their choice of subjects for the learners. Learners must choose the relevant subject and not take what is available in the centre. This means that the review of the curriculum needs to be done in order to cater for the needs of the learners.

- Learning environment need to be improved. This should be an effort that will engage the Department of Basic Education to try and locate a suitable venue for the centre. Adults should not be expected to sit in those young childrens' chairs and expect to concentration and be positive. Their classes need to have attractive charts relevant to the level they have registered for.

- LTSM is important to make learning relevant to the learners. There should be sufficient supply of the LTSM to all the learners. The programme offered to adult learners should cater for Functional Adult Literacy Programme (FALP). This programme will enable the learner to realise the need to stay and continue learning because it brings functionality in learning. FALP will assist learners with entrepreneur skills to alleviate poverty and start their own businesses.

\section{References}

Brookfield, SD. (2001). Understanding and facilitating adult learning, Great Britain: Open University Press.

Department of Education, (1997a). Policy for Adult Basic Education and Training. Pretoria, South Africa: Government printers.

Department of Education, (1997b). A National Multi-Year Implementation Plan for Adult Education and Training: Provision and Accreditation. Pretoria: National Department of Education.

Department of Education. (2010). South African Government Information Document, Basic Education, Policy and Curriculum Development. Pretoria: Government Printers

Department of Education, (2012). Statistical Overview of Schools and Adult Education Centre. Pretoria, South Africa: Government Printers.

De Vos A.S. (2011). Research at Grass roots. A primer for the caring professions. Pretoria: van Schaik.

Freire, P. (1970). Pedagogy of the oppressed. New York: Continuum International Publishing Group.

Freire, P. (1998). Pedagogy of the oppressed. Lanham: Rowman \& Littlefield.

Freire, P. (2005). Education for critical consciousness. New York: Continuum International Publishing Group.

Gouws, E. Kruger, N. \& Burger S. (2008). The adolescent. Third edition. Johannesburg: Heinemann Publishers.

Knowles, M. (1998). The Definite Classic in Adult Education and Human Resources Development, $5^{\text {th }}$ edition. Houston: Gulf Publishing Company.

Knowles, M.S. Holton, 111 E.F. and Swanson, R.A.(2005). The Adult Learner: The Definitive Classic in Adult Education and Human

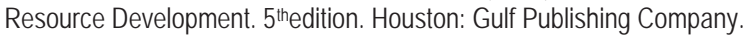

Knowles, M. (2011) Adult learner: The Definitive classic in adult education and Human Resource Development. Oxford: Elsevier.

Machingambi, S. (2013). Instructional strategies for motivating students: Reflections from 13 years of Teaching in Higher Education. International journal of Education science 5 (3):227-235.

O'Connor, E. (2002). The politics of management thought: A case study of Harvard Business School and the Human Relations School. Academy of Management Review 24(1) 117-131.

Okech, A. (2004). Participation in the JCAE world Assembly: Thematic workshop on documentation and on training of adult educators in adult education development. 58 pp 177-181.

Patrick R. (2008). Perspectives of change: A continued struggle for academic and cultural relevancy at an American Indian School in the midst of No Child Left Behind. Journal of American Indian Education.

Petri, H.L. \& Govern, J.M. (2004). Motivation: Theory, research applications (5 $5^{\text {th }}$ edition) Belmont, CA: Wodsworth.

Rogers, A. (2009). Adult Education and Development, Adult motivation: DDV international. Number 61.

White, C.J. (2005). Research a Practical Guide. Pretoria: Intuthuko.

Wotherspoon, T. (2004). The sociology of Education in Canada: Critical Perspectives. Toronto: Oxford University Press. 